\title{
THE RADIOLOGICAL AND BACTERIOLOGICAL ASSESSMENT OF TUBERCULOUS LUNG LESIONS REMAINING AFTER LONG TERM ALTERNATE-DAY DUAL DRUG CHEMOTHERAPY
}

\author{
Dr. A. W. T. EADE, B.Sc., M.B., M.R.C.P., D.Phys.Med. \\ Mr. G. KENT HARRISON, M.D., F.R.C.S. \\ Colonel S. E. LARGE, M.B.E., M.D., F.R.C.P. \\ Consultant in Medicine, A.D.M.S., H.Q., Cyprus District. \\ Brigadier J. MACKAY-DICK, O.B.E., M.B., F.R.C.P. \\ Consultant in Medicine, Inspector of Army Medical Services.
}

\begin{abstract}
WE have described previously studies of tuberculous lung lesions remaining after prolonged chemotherapy in a group of Gurkha patients (Eade et al, 1959). These patients were treated with streptomycin and isoniazid given together on alternate days for periods ranging from ten to twenty-five months following an initial period of daily therapy with the same drugs (Mackay-Dick, $1963 \mathrm{a}$ and b). The findings on long term follow up of these patients were later reported by Large and Dimond (1964). We report now a further group of patients similarly treated for nine to twenty-eight months before partial lung resection. The combined series comprises 95 patients in whom 98 partial lung resections were performed. The patients were treated initially at the British Military Hospital, Kinrara, Malaya (Mackay-Dick 1958) and were later transferred to the Connaught Hospital (Army Chest Centre) in this country. All matters relating to the general management of the patients were described previously. Streptomycin $1.0 \mathrm{~g}$ and isoniazid $200 \mathrm{mg}$ (in two $100 \mathrm{mg}$ doses) were given on each treatment day; the preliminary period of daily therapy was thirty, sixty or ninety days depending upon the initial assessment of the case. In the combined series approximately 15 per cent of the patients had daily therapy for ninety days, 30 per cent for sixty days and 55 per cent for thirty days.
\end{abstract}

\section{Radiological assessment of the disease and its behaviour during chemotherapy}

The extent of the disease present initially was such that of the 36 new cases, 28 were Group I (one zone involved), 7 were Group II ( 2 or 3 zones) and one Group III (4 or more zones). There was radiological evidence of cavitation in 16 patients; tomography showed 21 distinct cavities. 19 of the cavities were judged as small (maximum diameter less than $1.5 \mathrm{~cm}$ ), one medium (diameter between 1.5 and $2.5 \mathrm{~cm}$ ), and one large (diameter greater than $2.5 \mathrm{~cm}$ ). In this group all of the cavities closed during the period of pre-operative chemotherapy. Table I shows the time of closure of cavities in this group and in the combined series. Chemotherapy had been given for an average of sixteen months (range twelve to twenty-three months) in the 5 patients who still had cavities present at the time of operation. It will be seen that a cavity still present at nine months had only a 50 per cent chance of closing with further chemotherapy, and if this cavity had been larger than $2.5 \mathrm{~cm}$ diameter on admission, closure did not occur. The relation between cavity size and time of closure is shown in Table II. 
Table I

Fate of Cavities during prolonged alternate-day Chemotherapy

\begin{tabular}{l|c|c}
\hline \multirow{2}{*}{ Duration of Chemotherapy } & Number of cavities shown to have closed \\
\cline { 2 - 3 } & Present Series & Combined Series \\
\hline 3 months & 4 & 22 \\
\hline 6 months & 9 & 39 \\
\hline 9 months & 17 & 56 \\
\hline More than 9 months & 21 & 62 \\
\hline Failed to close before operation & 0 & 5 \\
\hline
\end{tabular}

Table II

Closure of Cavities related to Maximum Cavity Size

\begin{tabular}{l|c|c}
\hline \multicolumn{1}{c|}{ Diameter of cavity } & Number of cavities & Average time of closure (in months) \\
\hline Under $1.5 \mathrm{~cm}$ & 50 & 5 \\
\hline 1.5 to $2.5 \mathrm{~cm}$ & 6 & 6 \\
\hline Over $2.5 \mathrm{~cm}$ & 6 & 7 \\
\hline
\end{tabular}

A further five cavities, all initially of diameter greater than $2.5 \mathrm{~cm}$ failed to close.

\section{Radiological regression of disease related to duration of chemotherapy}

We considered that radiological stability had been reached when 3 consecutive routine films, taken at intervals of six weeks, had shown no change. This was achieved by about two thirds of the patients after one year, and by about 90 per cent after eighteen months chemotherapy. The findings for the combined series of 95 patients are presented in Table III. The average duration of chemotherapy for the 8 patients who did not achieve radiological stability was seventeen months (range twelve to twenty-three months). In the 6 patients showing no apparent radiological change the period of treatment averaged fifteen months (range nine to twenty-eight months). In one patient, noted in the previous

Table III

Radiological change related to duration of Chemotherapy

\begin{tabular}{l|c}
\multicolumn{1}{c|}{ Radiological state } & Number of patients \\
\hline Stability reached within 6 months & 20 \\
\hline Stability reached within 12 months & 61 \\
\hline Stability reached within 18 months & 80 \\
\hline Stability reached at time of operation & 8 \\
\hline No change during period of chemotherapy & 6 \\
\hline Radiological deterioration & 1 \\
\hline
\end{tabular}


series, following slow regression of non-cavitated disease, cavitation of a small 'solid' lesion occurred in the fifteenth month of chemotherapy. Sputum and laryngeal swab cultures remained negative. Partial lung resection was carried out a few weeks later; all cultures from the specimen were negative.

\section{Pre-operative bacteriological assessment}

Of the 36 patients in this series, Myco. tuberculosis was cultured from the sputum of 8 on admission. Repeated cultures of sputum or laryngeal swabs in the few weeks before operation were negative in all patients.

\section{Surgical aspects}

As with the previous series, all operations were performed at the Connaught Hospital by one surgeon. There were no deaths or major post-operative complications.

\section{Examination of the specimens}

Pooled material from each of the 38 specimens was cultured, and a guinea pig inoculated, at the Connaught Hospital. At the Institute of Diseases of the Chest, material from 110 individual lesions was taken for culture; two cultures were made by each of these, one after treating with tri-sodium phosphate, making a total of 220 samples.

In total, positive smears were obtained from 27 operation specimens, but positive cultures were obtained from only 3. Two specimens gave positive cultures in both laboratories; the other gave positive cultures at the Institute of Diseases of the Chest, but both culture and guinea pig inoculation were negative at the Connaught Hospital. The bacteriological results from this and the combined series are related to the duration of chemotherapy in Table IV.

Table IV

Bacteriology of resected specimens related to duration of Chemotherapy

\begin{tabular}{l|c|c}
\hline \multicolumn{1}{c|}{ Months of chemotherapy } & $\begin{array}{c}\text { Number of resected } \\
\text { specimens }\end{array}$ & $\begin{array}{c}\text { Number of specimens from } \\
\text { which viable bacilli } \\
\text { recovered }\end{array}$ \\
\hline $\begin{array}{l}\text { Present Series } \\
9 \text { to } 12 \text { months }\end{array}$ & 6 & 1 \\
12 to 15 months & 12 & 1 \\
15 to 18 months \\
more than 18 months & 73 & Nil \\
\hline $\begin{array}{l}\text { Combined Series } \\
9 \text { to } 12 \text { months }\end{array}$ & 11 & 2 \\
12 to 15 months & 34 & 3 \\
15 to 18 months \\
more than 18 months & 26 & 3 (1 resistant) \\
\hline \multicolumn{1}{c}{ TOTAL } & 98 & 1 (resistant) \\
\hline
\end{tabular}

The 2 patients who harboured resistant bacilli were described in the previous series; in these patients pre-operative laryngeal swab cultures also grew resistant organisms and the radiographs showed persistent cavitation. The initial sensitivity of the organisms was not established. If these 2 cases are omitted, on the grounds that the chemotherapy 
given was inadequate for them, the downward trend in culture positive results with the increasing duration of chemotherapy is apparent. From the resected specimens of the 11 patients who had nine to twelve months chemotherapy, 2 positive cultures were obtained (18 per cent). 34 patients had twelve to fifteen months chemotherapy, and the specimens from 3 gave positive cultures ( 9 per cent). From 25 patients who had chemotherapy for fifteen to eighteen months, 2 specimens were culture positive ( 8 per cent). None of the resected specimens from 26 patients who had more than eighteen months chemotherapy grew organisms on culture.

In order to obtain information concerning the influence of varying periods of chemotherapy on the bacteriology of specimens derived from patients with different types of disease, we divided the patients into 3 groups:

(A) those with cavities still present at the time of operation

(B) those in whom cavities initially had closed, and

(C) those in whom there had been no evidence of cavities at any stage.

(A) Cavities still present at time of operation. In the series reported previously (Eade et al, 1959) 5 patients, all of whom had been on chemotherapy for more than one year, still had cavities present at the time of operation; in addition in one patient a previously 'solid' lesion cavitated just before operation after fifteen months chemotherapy. In the present series no cavities persisted and no open cavities were demonstrated in the resected lung specimens.

(B) Disease with cavities closed before operation. There were 16 patients in whom all cavities had closed before operation. The resected specimens of none gave positive cultures. In the previous series there were 34 patients in this group and one gave a positive culture. The positive culture was obtained from the lung specimen of the only patient who had received drugs for less than six months after cavity closure; in addition he had been treated for less than one year in total.

(C) Specimens from patients with solid lesions throughout. Positive cultures were obtained from 3 of the 22 resected lung specimens of patients in this group (Table V).

Of the 42 patients with non-cavitated disease, Myco tuberculosis was cultivated from 5, all of whom had been on chemotherapy for less than eighteen months. The organisms recovered from 3 specimens were fully sensitive to the drugs in use. In the

Table V

Duration of Chemotherapy related to specimen bacteriology in those cases with solid disease (never cavitated)

\begin{tabular}{l|r|r}
\hline Months of Chemotherapy & $\begin{array}{c}\text { Number of resected } \\
\text { specimens }\end{array}$ & $\begin{array}{c}\text { Number of specimens from } \\
\text { which cultures positive }\end{array}$ \\
\hline Present Series & 4 & 1 \\
9 to 12 months & 7 & 1 \\
12 to 15 months & 4 & Nil \\
15 to 18 months & 7 & 1 \\
More than 18 months & & 2 \\
\hline Combined Series & 6 & 2 \\
9 to 12 months & 15 & Nil \\
12 to 15 months & 11 & 10 \\
15 to 18 months & & \\
More than 18 months & &
\end{tabular}


other 2 cases the cultures were positive in only one laboratory and since sub-cultures failed drug sensitivities could not be determined.

\section{Discussion}

An alternate-day regime in which one drug is injected and the administration of the oral drug at the same time witnessed, has the merit of certainty that the drugs have, in fact, been taken, involves outside attention only once in forty-eight hours, and reduces the drug bill. Thus if such regimes can be shown to be effective there is much to commend them (Tubercle, 1967). The regime described here was introduced in the Army Chest Centre in 1953 (Mackay-Dick, 1954) and subsequently used there and at the British Military Hospital, Kinrara, Malaya with satisfactory clinical and radiological results. (Mackay-Dick, 1963a, 1963b, and 1965; Eade et al, 1959). Reports from the Tuberculosis Chemotherapy Centre, Madras $(1960,1963,1964)$ have suggested that intermittent chemotherapy involving the use of streptomycin and isoniazid (in high dosage) together on two days of each week is effective and suitable for long term therapy. Recently, Stradling and Poole (1965) have reported favourably on a regime in which the continuation therapy has been streptomycin and a large $(600 \mathrm{mg})$ dose of isoniazid given together on alternate days.

Our findings show the alternate-day regime used to treat the patients in this series to be effective. The clinical and radiological behaviour of the disease during treatment differed little from that observed and reported with regimes of daily chemotherapy. In particular, cavity closure rates were as good as, or better than, those reported with daily chemotherapy. Sputum and laryngeal swab cultures became negative in all save 2 of the 95 patients; in these the organisms were resistant to the drugs in use, the only examples of resistance (approximately 2 per cent) in the series. Both of these patients had persisting cavities. The resistant strains may have developed during the course of treatment although this cannot be certain since the initial sensitivities were not established. The incidence of infection with initially resistant strains in the population indigenous to the countries (Malaya and Hong Kong) where these patients contracted tuberculosis is certainly greater than 2 per cent.

Of the 98 resection specimens positive cultures were obtained from only 9, despite many more cultures being set up than is the usual practice. Apart from one case, described previously, in which persistent cavitation and resistance occurred, positive cultures were not obtained from any specimen where chemotherapy had continued for eighteen months or longer. In those cases where cavity closure was shown to have occurred the prospect of sterilisation of the lesion was excellent ( 98 per cent) and appeared certain if chemotherapy had continued for more than six months following cavity closure. In these circumstances prolonged chemotherapy with this regime must be regarded as good definitive treatment.

A cavity persisting after nine months' therapy stood a poor chance of eventual closure, particularly if it had been large (greater than $2.5 \mathrm{~cm}$ in diameter) on admission. In addition there was a high chance ( 60 per cent) of persisting viable bacilli, and a significant risk ( 40 per cent) of these being resistant. These findings constitute a strong argument for resection of such disease, and the logical time at which to assess the necessity for surgery in patients with cavitated disease treated with this regime, would appear to be after nine months' chemotherapy. 
With disease which had never been shown to be cavitated, 5 specimens out of 42 were culture positive; in 4 of these patients chemotherapy had been given for more than one year and there had been comparatively little radiological change.

Of the 10 cases where chemotherapy had been given for longer than eighteen months all cultures were negative. Although these results were good they were less impressive than those obtained with cavitated disease. Since the duration of chemotherapy in the 'cavitated' and 'non-cavitated' group was similar, the length of the initial period of daily therapy was the major difference between them. In the patients with non-cavitated disease almost without exception the initial period of daily therapy was continued only for thirty days, whereas initial daily therapy for sixty or ninety days was the more usual procedure for the patients with cavitated disease.

In view of the significant risk of initial infection with resistant strains, a triple daily regime until the sensitivity of the infecting organisms has been established is the initial therapy of choice. Subsequently, treatment can be continued with a combination of two drugs to which the bacilli are known to be sensitive. Streptomycin and isoniazid given together on alternate days appears an effective regime which could be used in such circumstances.

\section{Summary}

A study of a group of 36 patients treated with the same regime of chemotherapy, namely streptomycin $1.0 \mathrm{~g}$ and isoniazid $200 \mathrm{mg}$ given together on alternate days following an initial period of daily therapy, is reported. A group of patients similarly treated was described in 1959; the combined series relates to 95 patients.

After a period of chemotherapy ranging from nine to twenty-eight months the residual disease was resected and subjected to bacteriological study at two hospitals.

At nine months 83 per cent of the cavities present initially had closed, and within eighteen months radiological stability had been achieved in about 90 per cent of the patients.

In the immediate pre-operative period resistant organisms were isolated from two of the patients, both of whom had persistent cavities; at this stage sputum or laryngeal swab cultures were negative in all of the other patients.

Positive cultures were obtained from 9 of the 98 resected specimens; 3 of these were associated with persistent cavities, one with disease in which cavity closure had occurred recently, and the remaining 5 with disease which had never been cavitated.

If all cavities had closed, viable bacilli could not be recovered from the lung specimen provided chemotherapy had been continued for six months following cavity closure.

Apart from one of the two cases from which drug resistant organisms were cultured, no positive cultures were obtained from the lung specimens from patients who had received more than eighteen months chemotherapy regardless of the type of disease.

The clinical, radiological and bacteriological findings suggest that this regime is effective therapy.

\section{Acknowledgements}

We are indebted to Dr. R. W. Riddell and Dr. Lynne Reid for their co-operation and advice, and would like to thank the staffs of the bacteriology departments of the Brompton Hospital, The Institute of Diseases of the Chest, and the Connaught Hospital. 


\section{REFERENCES}

Eade, A. W. T., Harrison, G. K., Large, S. E., Mackay-Dick, J. Reid, L., and Riddall, R. W. (1959). Thorax 14., 104.

LARGE, S. E. and Dimond, A. H. (1964). Tubercle (Lond.) 45, 336.

LEADING ARTICLE, (1967), Tubercle (Lond.) 48, 58.

MACKAY-DICK, J., (1954). Lancet ii, 44.

MACKAY-DICK, J., (1958), N.A.P.T., Commonwealth Chest Conference Transactions, London.

MACKAY-DICK, J., (1963a). Lancet i, 1429.

MACKAY-DiCK, J., (1963b). J. roy. Army med. Corps 109, 255.

MACKAY-DICK, J. (1965). Brit. med. J., 2, 232.

Stradling, P. \& Poole, G. (1965). Tubercle (Lond.) 45, 290.

Tuberculosis Chemotherapy Centre, (1960). Bull. Wld. Hlth. Org. 23, 535.

Tuberculosis Chemotherapy Centre, (1963). Lancet i, 1078.

Tuberculosis Chemotherapy Centre (1964). Bull. Wld. Hlth. Org. 31, 247.

\section{Sir Arthur Porrit, Bt.}

It has been notified that " Medicine Today" has published a special supplement as a tribute to Sir Arthur Porritt, Bt., guest-edited by Sir Clement Price-Thomas, London, and Sir Douglas Robb, New Zealand.

The contents of the supplement (to Vol 1, No. 4 of Medicine Today) are as follows:

\section{CONTENTS}

Arthur Porritt in New Zealand. Sir Douglas Robb, Auckland, New Zealand.

Personal Memoirs-Days of Youth. Trevor DeC. Low; Roland Perry; Robert

Williams: Canon N. Williams; M. Kronfield.

Sir Arthur Porritt--Olympic Runner. The Most Hon. The Marquess of ExeTer.

Arthur Porritt-Personal Memoirs of an Athlete. George R. Kingston.

The Military Career of Sir Arthur Porritt, Bt. G. A. G. Mitchele.

Sir Arthur Porritt-An United States Tribute. Loyal Davis.

Sir Arthur Porritt, Bt. \& James IV Association of Surgeons. SIR JoHn BruCE: J. William Hinton.

Sir Arthur Porritt-President, Royal College of Surgeons. Sir Clement Price Thomas, K.C.V.O.

Arthur Espie Porritt-International Surgeon. WALter McKenziE.

Sir Arthur Porritt and the Commonwealth Medical Association. Derek Stevenson.

Sir Arthur Porritt, LL.D. (N.Z.) Hon. Causa. K. J. Maidment.

Sir Arthur Porritt-Recessional \& Prospect. Roeington B. Khambatta.

Sir Arthur Porritt-Scholar, Sportsman, Soldier, Surgeon, Statesman. KHORSHED MOBED.

Copies are available at either 7s. 6d. or U.S. $\$ 1.00$ post-paid (sea Mail) from the Publishing Department, Medicine Today, 3, Hoshang Road, Karachi-4, Pakistan. 